\title{
The cause of turbidity in lyophilised plasmas and its effects on coagulation tests
}

\author{
C F Hirst, L Poller
}

\begin{abstract}
Aims: To investigate the cause of turbidity in reconstituted lyophilised plasmas and to determine its effect on coagulometers. Methods: The turbidities of 20 normal plasmas and 16 reconstituted lyophilised plasmas were determined by comparing a 1 in 4 dilution in distilled water with a standard suspension in an Aminco Fluorocolorimeter (American Instrument Co) in nephelometric mode. The turbidities of five other plasmas were determined before and after lyophilisation. The turbid components of fresh and reconstituted lyophilised plasmas were studied using electron microscopy. The effects of turbidity on five types of coagulometer were determined by adding varying concentrations of a turbidity enhancing material.
\end{abstract}

Results: Reconstituted lyophilised plasmas were more turbid than normal plasmas, because of agglomerated liposomes. Serum depleted of chylomicrons and very low density lipoproteins was not rendered more turbid by lyophilisation. Three out of five types of automated coagulometer tested gave activated partial thromboplastin times which were appreciably affected by plasma turbidity. One of the instruments was unable to detect a clot in a moderately turbid plasma. A second instrument gave results which were significantly affected by turbidity. Turbidity of the substrate plasma did not affect specific factor VIII assays in two types of coagulometer.

Conclusions: Lyophilisation of plasma induces turbidity due to the agglomeration of lipids. Such turbidity can affect the results of coagulation tests. Suppliers of lyophilised plasmas should be aware of this problem.

Plasma is naturally turbid. Turbidity of serum is caused by the presence of lipid containing complexes, chylomicrons, and very low density lipoproteins (VLDL). ${ }^{1}$ The turbidity of plasma is probably attributable to the same factors. Reconstituted lyophilised plasmas are invariably more turbid than the plasmas from which they are prepared. Such turbidity may be undesirable if the plasmas are to be used in coagulometers based on nephelometric or absorptiometric principles.

\section{Methods}

PLASMA TURBIDITY MEASUREMENTS

The technique was based on a method for the measurement of water turbidity, described by the American Water Works Association and the American Public Health Association. ${ }^{2}$ Hydrazine sulphate $\left(\left[\mathrm{NH}_{2}\right]_{2} \mathrm{H}_{2} \mathrm{SO}_{4}\right)$ (Sigma) $1.0 \mathrm{~g}$ and hexamethylenetetramine (Sigma) $10.0 \mathrm{~g}$ were each dissolved in $100 \mathrm{ml}$ of distilled water. Five $\mathrm{ml}$ of each solution were mixed, diluted to $100 \mathrm{ml}$ with distilled water, and incubated at $26^{\circ} \mathrm{C}$ for 24 hours. This solution gradually develops a stable turbidity due to the formation of formazin polymer particles. A value of 400 nephelometric turbidity units (NTU) was ascribed to this suspension. From this a series of working standards from 0-200 NTU were prepared. The turbidities of 20 normal plasmas and 16 reconstituted lyophilised plasmas were determined by comparing a 1 in 4 dilution in distilled water with a standard suspension in an Aminco Fluorocolorimeter (American Instrument Company) in nephelometric mode. The 16 lyophilised plasmas comprised seven obtained commercially and nine lyophilised in our laboratory. The turbidities of five further plasmas were determined before and after lyophilisation.

ELECTRON MICROSCOPY

Electron microscopic studies were performed on fresh and reconstituted lyophilised plasmas. One millilitre of each plasma was added to $1.0 \mathrm{ml}$ of distilled water and $3.0 \mathrm{ml}$ of $30 \mathrm{~g} / 1$ gluteraldehyde added. These preparations were centrifuged at $65000 \times g$ for one hour. Aliquots of the upper turbid layers were applied to pialoform (Agar Scientific) coated electron microscopy grids and dried in air. They were then examined in a Philips EM420 transmission electron microscope (magnification between $\times 10000$ and $\times 105000)$.

TURBIDITY OF SERA DEPLETED OF LIPOPROTEINS Four serum samples of varying lipid content were obtained from the Department of Biochemistry at Withington Hospital, Manchester. These comprised lipid rich, chylomicron and VLDL depleted, chylomican VLDL and low density lipoprotein (LDL) depleted, and lipid free. A fifth serum, devoid of chylomicrons alone, was prepared by centrifugation of lipid rich serum at $3000 \times g$ and removal of the upper layer. The turbidity of these sera was determined before and after lyophilisation. 

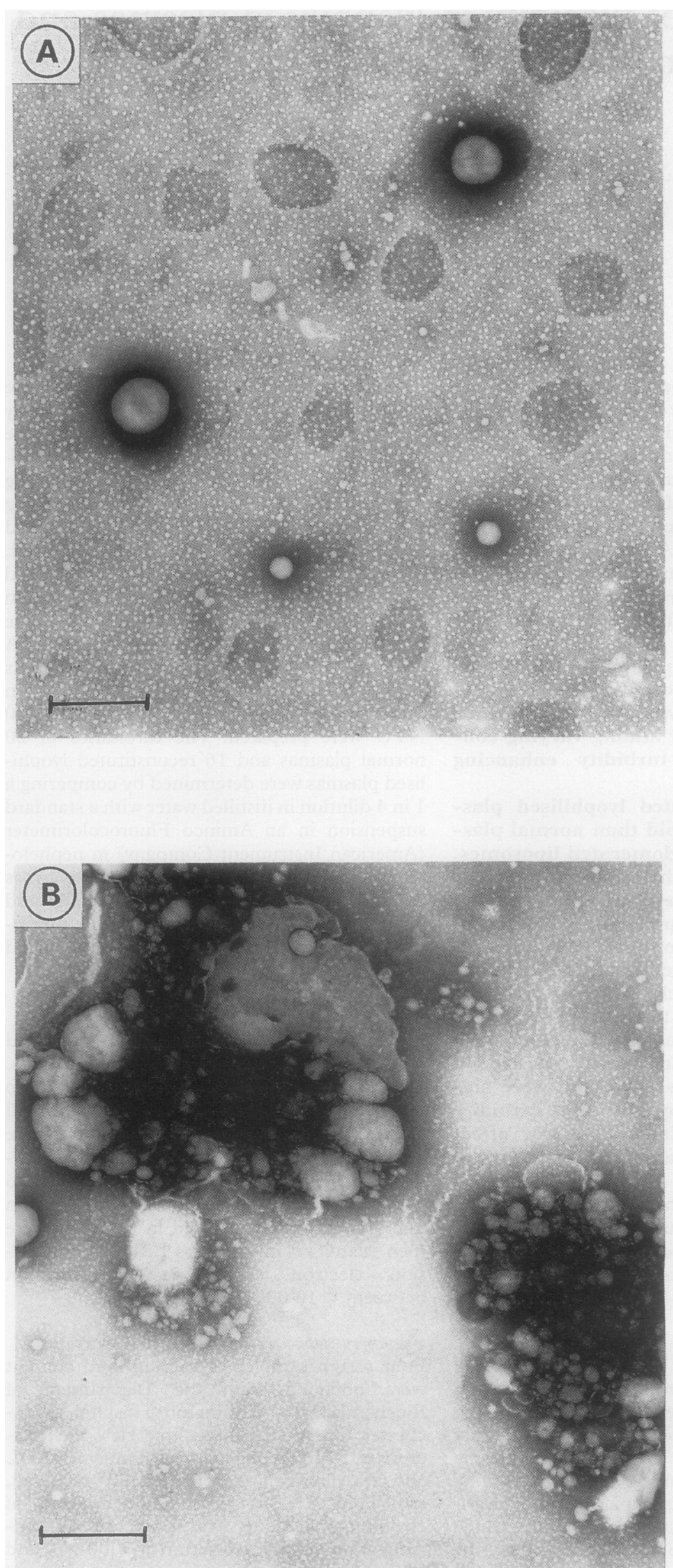

Electron micrographs of the turbid fraction of natural $(A)$ and reconstituted lyophilised (B) plasmas. Scale bar $=600 \mathrm{~nm}$.
EFFECT OF PLASMA TURBIDITY ON COAGULOMETERS The turbidity of several aliquots of one plasma was varied by adding standard volumes of the standard formazin suspension. Activated partial thromboplastin times (APTT) by the Manchester APTT method ${ }^{3}$ were performed on five types of caogulometer: Amelung $\mathrm{KC10}$ (Baxter), IL 300R (Instrumentation Laboratory), IL 810 (Instrumentation Laboratory), MLA Electra 700 (Lab Medics) and Coagamate $\times 2$ (Organon Teknika). Factor VIII assays were also carried out on the plasma series using the two different models of coagulometer from Instrumentation Laboratory (IL $300 \mathrm{R}$ and IL 810). Formazin suspension was added to a relatively clear factor VIII deficient plasma to test the effect of substrate plasma turbidity in an APTT based on stage factor assay.

\section{Results}

The mean (SD) turbidities of fresh and reconstituted lyophilised plasmas were 344 (126) and 1179 (56) NTU, respectively. The mean (SD) of the commercially obtained and locally prepared reconstituted lyophilised plasmas were 1533 (637) and 904 (351), respectively. The turbidities of fresh and reconstituted plasmas were compared by unpaired $t$ test and found to be significantly different $(p<0.05)$. The mean (SD) turbidity of the five plasmas tested before and after lyophilisation were 416 (181) and 715 (280), respectively. These were compared by paired $t$ test and found to be significantly different $(p<0.05)$.

Electron microscopic examination showed that fresh and reconstituted lyophilised plasmas were significantly different. Fresh plasma contained lipid rich particles of between 150 and $300 \mathrm{~nm}$ in diameter. Reconstituted lyophilised plasma contained large lipid rich agglomerates of up to $4 \mu \mathrm{m}$ diameter, which showed structural liposome rearrangement. The commercially obtained plasmas contained the largest agglomerates. Electron micrographs of fresh and reconstituted commercially obtained lyophilised plasmas are shown in the figure.

The turbidity values of the sera series depleted of liposomes are shown in table 1 . Chylomicrons and VLDL were responsible for the increased turbidity of lyophilised plasmas.

The APTT values of aliquots of a single plasma with turbidity values artificially adjusted to between 264 and 3484 NTU, as measured on five coagulometers, are shown in table 2. The Amelung KC10, IL 300R, and MLA Electra 700 seemed to show no turbidity induced effects. The IL 810 was unable to detect the clot in a sample with a turbidity of more than 1216 NTU. The Coagamate $\times 2$ gave an APTT value which increased with turbidity. These relations were compared by regression analysis and the significance of the observed correlations was tested by the $\mathrm{F}$ test. A significant correlation $(p<0.05)$ between turbidity and APTT was found in the Coagamate $\times 2$ and the IL 300 R. The tight precision 
Table 1 Turbidity values before and after lyophilisation of a series of sera of differing lipoprotein content

\begin{tabular}{lll}
\hline Serum type & $\begin{array}{l}\text { Pre-lyophilisation } \\
\text { turbidity (NTU) }\end{array}$ & $\begin{array}{l}\text { Post-lyophilisation } \\
\text { turbidity (NTU) }\end{array}$ \\
\hline Serum & 500 & 720 \\
Serum depleted of chylomicrons & 440 & 720 \\
Serum depleted of chylomicrons and VLDL & 500 & 760 \\
Serum depleted of chyclomicrons VLDL and LDL & 200 & 280 \\
Lipid free serum & 200 & 220 \\
\hline
\end{tabular}

Table 2 APTT values (seconds) of a single plasma "spiked" with varying levels of turbidity tested on five coagulometers

\begin{tabular}{llllll}
\hline $\begin{array}{l}\text { Turbidity } \\
\text { (NTU) }\end{array}$ & $\begin{array}{l}\text { Amelung } \\
\text { KC10 }\end{array}$ & IL 810 & IL 300R & $\begin{array}{l}\text { Organon } \\
\text { Coagamate } \times 2\end{array}$ & $\begin{array}{l}\text { MLA } \\
\text { Electra } 700\end{array}$ \\
\hline 264 & $35 \cdot 0$ & $37 \cdot 8$ & $29 \cdot 8$ & $26 \cdot 3$ & $33 \cdot 0$ \\
411 & $34 \cdot 3$ & $39 \cdot 8$ & $29 \cdot 8$ & $25 \cdot 8$ & $31 \cdot 6$ \\
571 & $34 \cdot 5$ & $39 \cdot 4$ & $30 \cdot 0$ & $27 \cdot 5$ & $32 \cdot 0$ \\
896 & $35 \cdot 7$ & $38 \cdot 6$ & $29 \cdot 8$ & $28 \cdot 5$ & $33 \cdot 0$ \\
969 & $35 \cdot 5$ & $41 \cdot 0$ & $29 \cdot 7$ & $29 \cdot 3$ & $32 \cdot 5$ \\
1067 & $34 \cdot 4$ & $41 \cdot 3$ & $30 \cdot 0$ & $29 \cdot 2$ & $32 \cdot 6$ \\
1216 & $35 \cdot 0$ & CE & $30 \cdot 2$ & $30 \cdot 0$ & $32 \cdot 4$ \\
1560 & $34 \cdot 9$ & CE & $30 \cdot 0$ & $29 \cdot 4$ & $32 \cdot 4$ \\
1738 & $35 \cdot 2$ & CE & $30 \cdot 5$ & $29 \cdot 6$ & $32 \cdot 1$ \\
2082 & $35 \cdot 2$ & CE & $30 \cdot 4$ & $29 \cdot 6$ & $32 \cdot 6$ \\
2329 & $34 \cdot 6$ & CE & $31 \cdot 1$ & $30 \cdot 3$ & $32 \cdot 2$ \\
2525 & $35 \cdot 3$ & CE & $30 \cdot 5$ & $30 \cdot 3$ & $33 \cdot 0$ \\
2671 & $35 \cdot 2$ & CE & $30 \cdot 7$ & $30 \cdot 4$ & $32 \cdot 6$ \\
3007 & $35 \cdot 0$ & CE & $30 \cdot 9$ & $30 \cdot 1$ & $32 \cdot 4$ \\
3289 & $34 \cdot 9$ & CE & $30 \cdot 6$ & $31 \cdot 0$ & $32 \cdot 5$ \\
3484 & $34 \cdot 4$ & CE & $30 \cdot 2$ & $31 \cdot 2$ & $32 \cdot 3$ \\
\hline
\end{tabular}

$\mathrm{CE}=$ Coagulation error apolipoprotein, give the liposomes increased water solubility. The observed effects were probably due to liposome membrane fusing as previously described. ${ }^{4}{ }^{6}$ Lyophilised material has been found to be unreliable in the assay of cholesterol $^{7}$ and apolipoproteins. ${ }^{8}$ This may be due to the changed characteristics of lyophilised liposomes.

The turbidity measurements of sera depleted in liposomes showed that lyophilisation induced turbidity is caused mainly by chylomicrons and VLDL.

The observed effects of plasma turbidity on coagulometers is important. The mean turbidity of lyophilised plasmas was only slightly less than the value which adversely affected the IL 810 (1179 $v 1216 \mathrm{NTU}$ ). This isntrument has been superseded but many remain in use. The Coagamate $\times 2$ and the IL $300 \mathrm{R}$ gave APTT values which varied with turbidity. The high precision of the IL $300 \mathrm{R}$ allows a small upward drift to be detected but this is not of any real importance. The results with the Coagamate $\times 2$ gave more cause for concern. A five second difference is evident between the least and most turbid plasmas. Users of this instrument would obtain a result on a reconstituted lyophilised plasma which could be significantly affected by its turbidity. Lipaemic samples could also give the same effect. Such plasmas have been shown to have turbidities of up to 6800 NTU.

In conclusion, turbidity induced by lyophilisation is caused by lipids and can affect the results of coagulation tests. Suppliers of lyophilised plasmas should be aware of this problem.

actor VIII assays performed on both of IL coagulometer provided no significant correlation between plasma turbidity and factor concentration (data not shown) (factor assays were performed on these instruments because they use different clot detection principles when performing factor assays). Increasing the turbidity of a factor VIII deficient plasma from 520 to 1520 and 3520 NTU did not significantly affect the results obtained when assaying factor VIII concentrations of 20 and $100 \mathrm{IU} / \mathrm{dl}$ on either model of IL coagulometer.

\section{Discussion}

Lyophilisation significantly increased plasma turbidity. Electron microscopy showed that the turbidity was due to structural rearrangement and agglomeration of the lipid vehicles in plasma. The different liposomes in plama contain different quantitites of cholesterol, triglyceride, and phospholipid. The latter, being present in the liposome surface with

We thank Dr A Curry for assistance with the electronmicrography and to Dr A Duffy for providing the lipid depleted sera.

1 Gray CH, Howorth PJN. Clinical chemical pathology. London: Edward Arnold, 1979:135-49.

2 American Water Works Association and American Public Health Association. Standard methods for the examination of water and waste water. Washington, DC: APHA, 1985:133-40.

3 Thomson JM, Poller L. The activated partial thromboplastin time. In: Thomson JM, ed. Blood coagulation and haemostasis: A practical guide. Edinburgh: Churchill Livingstone, 1985:301-39.

4 Strauss G, Schurtenberger P, Hauzer $H$. The interaction of saccharides with lipid bilayer vesicles; stabilisation during freeze-thawing and freeze-drying. Biochim Biophys Acta 1986;858: $169-80$

5 Womersley CM, Uster PS, Rudolph AS, Crowe JH. Inhibition of dehydration induced fusion between liposomal membranes by carbohydrates as measured by fluoresence energy transfer. Cryo Biol 1986;23:245-55.

6 Crowe JH, Crowe M. Factors affecting the stability of dry liposomes. Biochim Biophys Acta 1988;939:327-34.

7 Kroll MH, Chester R. Effect of serum lyophilisation on the rate constants of enzymic methods for measuring cholesterol. Clin Chem 1990;36:534-7.

8 Marcovina SM, Adolphson JL, Parlavecchia M, Albers JJ. Effects of lyophilisation of serum on the measurement of apolipoproteins A-I and B. Clin Chem 1990;36:366-9. 